\title{
Storm time changes in total electron content in ionosphere measured by low orbiting topside sounder
}

\author{
N. Beloff ${ }^{1}$, P. F. Denisenko ${ }^{2}$, I. I. Ivanov ${ }^{2}$, O. A. Maltseva ${ }^{2}$, M. P. Gough ${ }^{1}$, S. I. Klimov ${ }^{3}$, M. N. Nozdrachev ${ }^{3}$, \\ H. Alleyne ${ }^{4}$, and I. Bates ${ }^{4}$ \\ ${ }^{1}$ Space Science Centre, Sci Tech, University of Sussex, Brighton, UK \\ ${ }^{2}$ Rostov State University, Rostov-on-Don, Russia \\ ${ }^{3}$ Space Research Institute, Russian Academy of Sciences, Moscow, Russia \\ ${ }^{4}$ Department of Automatic Control and System Engineering, University of Sheffield, Sheffield, UK
}

Received: 18 July 2003 - Revised: 12 February 2004 - Accepted: 30 March 2004 - Published: 7 September 2004

\begin{abstract}
A new experimental technique is presented for the determination of the total electron content (TEC) below a low-orbiting satellite. According to this technique TEC can be obtained using the segment of a topside ionogram that only contains the traces of signals reflected from the Earth's surface. Possibilities of this technique were demonstrated using MIR station topside sounding data at the night time for both quiet and disturbed ionospheric conditions, and in particular, during the 14 November 1998 storm. An interesting fact was revealed with the help of this technique: after a series of relatively strong storms the main ionospheric trough on 14 November 1998 was detected at an abnormally low geomagnetic latitude $\left(\sim 43^{\circ}\right)$. During this study some spatial variations of TEC were registered that can be interpreted as a TID-type wave structure.
\end{abstract}

Key words. Ionosphere (ionospheric disturbances; plasma temperature and density; instruments and techniques)

\section{Introduction}

Despite the fact that the interactions of the various nearEarth space plasma regions with the interplanetary magnetic field and solar wind have been known for several decades (Williams, Mead, 1968), various aspects of this process continuing to attract intensive research today (Dymond, 2001). In particular, one of the major indications of magnetosphereionosphere coupling is the significant variation of electron density in the ionosphere during a storm (Buonsanto, 1999; Danilov, 2001). Investigation of spatial temporal variations of electron density utilizes data from a number of instruments: incoherent scattering radars (Buonsanto et al., 1992), GPS systems (Hofmann-Wellenhof et al., 1992; Davies et al., 1997; Afraimovich et al., 2000; Leitinger et al., 1997; Schreiner et al., 1998), ground-based ionosondes (Danilov,

Correspondence to: N. Beloff

(n.beloff@sussex.ac.uk)
2001; Scali and Reinisch B. W., 1997) and satellite sounders (Pulinets and Benson, 1999).

After the initial success in the study of global ionospheric structure and its interactions with the plasmasphere during both quiet and disturbed periods using satellite sounding (Muldrew, 1965; Rycroft and Thomas, 1970), interest in this measurement technique waned. However, there has been a renewal of interest in recent times. This sounding technique was applied to magnetospheric plasma research (Calvertet al., 1995) and fundamental new results were obtained using "old" data from satellites Intercosmos-19, Cosmos-1809 and ISS-b (Karpachev, 2001).

In Russia the topside ionospheric sounding has been continued successfully and in 1998-1999 the ionosonde AI840 operated on board orbital complex (OC) MIR (Danilkin, 2001). These measurements are very important for global ionospheric monitoring regarding the technological use of the near-Earth space. In fact, global ionospheric models cannot replace this monitoring, because these models give an accuracy range from 5\% to $140 \%$ for the prediction of an electron density value at a fixed height (Szuszczewicz et al., 1998). In this paper most attention is paid to low-orbit satellites, which have significant advantages compared to highorbit satellites (Danilkin, 2002). In particular, due to the proximity of MIR orbit altitude to the F-region maximum height the errors in auroral ionospheric measurements are significantly decreased despite the high horizontal gradients of the electron density.

The authors discuss the possible use of low-orbit satellites with an ionosonde on board both for studying the physics of the ionospheric processes and for prediction of ionospheric parameter values. These possibilities are related to a determination of the ionospheric trough characteristics near the F-region maximum, and to an estimation of the ionospheric part of the total electron content (TEC) along the satellite's orbit.

Certainly, the ionisation trough is one of the most important structures, which, despite long-term research, remains the least predictable one, especially during the storm 

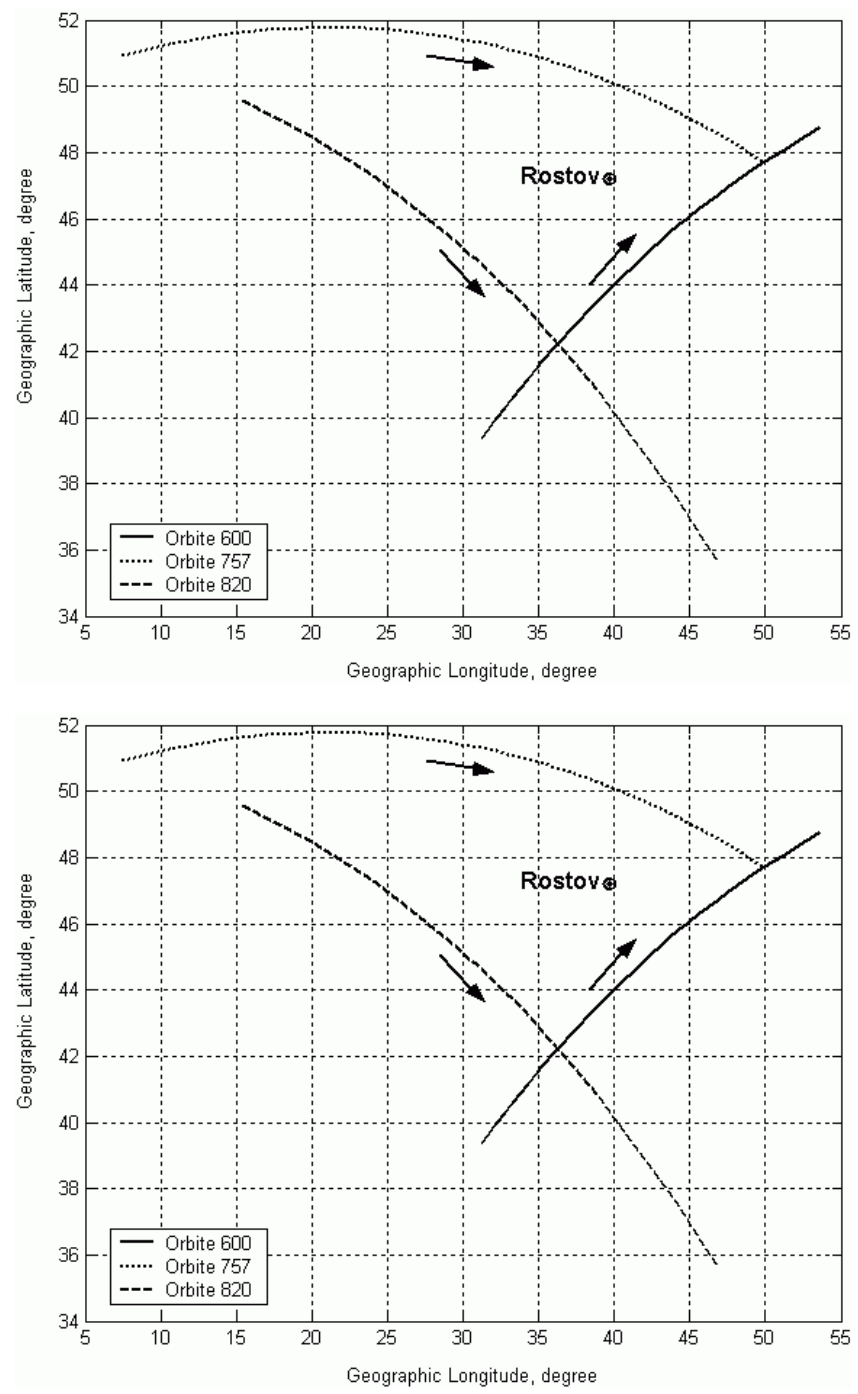

Fig. 1. Geographical and geomagnetic co-ordinates of the MIR station for three sample orbits.

recovery phase when it splits in two structures: main (MIT) and ring (RIT) ionospheric troughs (Deminov et al., 1995). An error of $\pm 5 \%$ in the trough position determination can lead up to an order of magnitude error in the determination of electron density N. This occurs because the trough boundaries can be confused with the effects caused by some other (for instance, sub-auroral) structures (Eliseev et al., 1995). Authors believe that existing discrepancies in trough parameter estimation are caused by low spatio temporal data resolution. In the case of AI-840 measurements the ionogram reading occurs every $8 \mathrm{~s}$, resulting in a good spatio temporal resolution.

The second application is related to the TEC estimation along the satellite orbit. In present paper the method is described that had been developed by authors for the determination of the TEC using traces of signals reflected from Earth. This method provides an estimate of the ionospheric contribution to the TEC value and, where necessary, provides a correction to the global ionospheric model (for example, IRI) using the current data.

In this paper the experimental results are presented for the period 4-18 November 1998, which includes magnetic storms, in particular the 13-17 November 1998 storm. Geomagnetic data confirms that here we are looking at a strong magnetic storm (Gonzalez, 1994). In Sect. 2 the details of the experiment are presented. In Sect. 3 the method for determination of the TEC using signals reflected from the Earth is described. In Sect. 4 the results are discussed and Sect. 5 contains the conclusion.

\section{The experiment}

Topside ionospheric sounding from on board of orbital complex (OC) MIR was carried out using ionosonde AI-840. It was performed at a total of 338 fixed frequencies, with a 25$\mathrm{kHz}$ step within the range $0.3-1.5 \mathrm{MHz}$ and a $50-\mathrm{kHz}$ step within $1.5-19.95 \mathrm{MHz}$ range. The transmitter's impulse duration was $133 \mu \mathrm{s}$, with a repetition frequency of $58.3 \mathrm{~Hz}$. Every $8 \mathrm{~s}$ one ionogram was registered, with an actual measurement time of $6 \mathrm{~s}$. The transmitter and the receiver were connected via a switch to the $15-\mathrm{m}$ dipole antenna. The transmitter power during an impulse was $200 \mathrm{~W}$. Ionosonde measured data were transmitted to the ground station via a telemetry channel of $137 \mathrm{MHz}$ as a set of analogue and digital signals. The ionogram itself was then reconstructed at the ground station. Examples of this process are presented in Danilkin (2001).

Ionograms were recorded at the ground station Rostov (latitude $47^{\circ} 13^{\prime} \mathrm{N}$, longitude $39^{\circ} 41^{\prime} \mathrm{E}$ ) when OC MIR was in the direct radio-visible zone at distances up to $2000 \mathrm{~km}$. The experiments were carried out episodically and were not assigned to any particular geophysical event. However, the authors succeeded in obtaining data covering approximately the same universal time (UT), but on different days before the strong ionospheric storm (4 November 1998, 1.25 UT, orbit 600), during the storm (14 November 1998, 1.22 UT, orbit $757)$ and after it (18 November 1998, 1.38 UT, orbit 820). On Fig. 1 geographical (Fig. 1a) and geomagnetic (Fig. 1b) co-ordinates of these relevant orbits are shown.

Geophysical conditions for this time period are shown on Fig. 2 via $D_{s t}$ (Fig. 2a) and $K_{p}$ (Fig. 2b) indices. The time of the measurements is marked by vertical pointers. It is clear from the graphs that orbit 600 fell into slightly disturbed conditions after 3 quiet days $\left(D_{s t} \sim 0\right)$. In the period between orbit 600 and orbit 757 several magnetic storms with high $K_{p}$ indexes took place. These storms can be classified as strong storms (Gonzalez, 1994). However, by 13 November 1998, the geophysical conditions returned to $D_{s t}$ and $K_{p}$ having levels typical for quiet conditions. On 13 November 1998 a single classic magnetic storm began with orbit 757 occurring during the beginning of the recovery phase and orbit 820 at the end of this phase. 


\section{The TEC determination using the traces of signals re- flected from the Earth}

Ionograms for all three orbits were recorded during the night time, when OC MIR was at an approximate height $\mathrm{h}_{s}=365 \mathrm{~km}$. Satellite height $\mathrm{h}_{s}$ was very close to the maximum height of the F-region $\mathrm{h}_{m} \mathrm{~F}$. Therefore, the traces of signals reflected from the topside of the ionosphere were recorded in a narrow band of frequencies. Records presented have a low quality due to a strong deflective absorption. This condition prevented the possibility of restoring the electron density profile $\mathrm{N}(\mathrm{h})$ above the $\mathrm{F}$ region maximum to determine $h_{m} F$. Therefore, the results of calculations are based on measurements of the group paths of signals reflected from the Earth. This permits us to determine the total electron content (TEC) below the MIR orbit.

Observations were carried out at the night time, therefore, the plasma influence in the D- and E-regions is negligible. The whole plasma layer below the satellite was approximated by the equivalent parabolic distribution

$f_{N}^{2}(h)=f_{m}^{2}\left[1-\left(\frac{h_{s}-h}{H_{p}}\right)^{2}\right]$,

where $f_{N}$ is the electron plasma frequency; $f_{m}$ is the critical frequency of the $\mathrm{F}$ region, $h_{s}$ is the satellite height and $H_{p}$ is a half-thickness of the parabola. The group paths of signals reflected from the Earth can be presented in the form:

$P^{\prime}(f)=h_{0}+\int_{h_{s}-H_{p}}^{h_{s}} \mu^{\prime}\left(f, f_{H}, \theta\right) d h$,

where $f$ is the sounding frequency; $f_{H}$ is the gyrofrequency; $\theta$ is the angle between the vertical and vector of intensity of the geomagnetic field; $h_{0}$ is the height of the equivalent base layer (1). Group refractive indices $\mu^{\prime}$ for ordinary (o) and extra-ordinary $(\mathrm{x})$ polarised waves can be presented in the form: (Paul, 1967)

$\mu_{o}^{\prime}=\frac{M_{o}(X, Y, \theta)}{\sqrt{1-X}}, \quad X=\frac{f_{N}^{2}}{f^{2}}, \quad Y=\frac{f_{H}}{f}$,

$\mu_{x}^{\prime}=\frac{M_{x}(X, Y, \theta)}{\sqrt{1-\tilde{X}}}, \quad \tilde{X}=\frac{X}{1-Y}$.

Considering the last formulae, expression (2) for the parabolic layer (1) finally can be seen as:

$P^{\prime}(f)=h_{o}+H_{p} \varphi(f)$,

where for o-waves

$$
\begin{aligned}
& \varphi_{o}=\frac{1}{\sqrt{X_{m}}} \int_{a}^{b} M_{o}[X(t), Y, \theta] d t, \\
& X(t)=1-\frac{1}{4}\left[\exp (t)+\left(1-X_{m}\right) \exp (-t)\right]^{2},
\end{aligned}
$$

$X_{m}=f_{m}^{2} / f^{2}, a=\ln \sqrt{1-X_{m}}, \quad b=\ln \left(1+\sqrt{X_{m}}\right)$.

For $\mathrm{x}$-waves similar expressions are:

$\varphi_{x}=\frac{1}{\sqrt{\tilde{X}_{m}}} \int_{a}^{b} M_{x}[X(t), Y, \theta] d t$,

$X(t)=(1-Y)\left\{1-\frac{1}{4}\left[\exp (t)+\left(1-\tilde{X}_{m}\right) \exp (-t)\right]^{2}\right\}$

$\tilde{X}_{m}=X_{m} /(1-Y), a=\ln \sqrt{1-\tilde{X}_{m}}, b=\ln \left(1+\sqrt{\tilde{X}_{m}}\right)$.

For the discrete frequency set the expression (3) can be rewritten as an over-determined system of equations with two unknown values, $h_{0}$ and $H_{p}$,

$P_{i}^{\prime}=h_{0}+H_{p} \varphi_{i}$

where $P_{i}^{\prime}=P^{\prime}\left(f_{i}\right), \quad \varphi_{i}=\varphi\left(f_{i}\right), \quad i=1,2, \ldots, n$. Let us assume that the errors $\varepsilon_{i}$ in the signal group path measurements: 1) do not depend on sounding frequency (i.e. the condition of frequency ergodicity is fulfilled); 2) have zero mean values $\left\langle\varepsilon_{i}\right\rangle=0$ and the same variance $\left\langle\varepsilon_{i}^{2}\right\rangle=\sigma^{2}$. In this case the following is true for an error sample mean:

$\bar{\varepsilon}=\frac{1}{n} \sum_{i=1}^{n} \varepsilon_{i} \approx 0$.

Since each value of the group paths can be presented as a sum

$P_{i}^{\prime}=P_{e, i}^{\prime}+\varepsilon_{i}$

of accurate value $P_{e, i}^{\prime}$ and the measurement error $\varepsilon_{i}$, then, considering formula (4), the sample mean for group path can be presented as

$\bar{P}^{\prime}=\bar{P}_{e}^{\prime}=h_{0}+H_{p} \bar{\varphi}$,

$\Delta \boldsymbol{P}^{\prime}=\hat{A} H_{p}$,

where the elements of vector-column $\Delta \boldsymbol{P}^{\prime}$ and matrixcolumn $\hat{A}$ are

$\Delta P_{i}^{\prime}=P_{i}^{\prime}-\bar{P}^{\prime}, \quad A_{i}=\varphi_{i}-\bar{\varphi}, \quad i=1,2, \ldots, n$.

Resolving system (5) by the Least-Squares Method (LSM), one can obtain the half-thickness of parabola (Plackett, 1960)

$H_{p}=\left(\hat{A}^{T} \hat{A}\right)^{-1} \hat{A}^{T} \Delta \boldsymbol{P}^{\prime}$

and estimate its mean-square error

$s\left(H_{p}\right)=\sqrt{\frac{S_{\min }\left(\hat{A}^{T} \hat{A}\right)^{-1}}{n-2}}$,

where the sum $S_{\min }$ of square residuals for the group paths is

$S_{\min }=\left(\Delta \boldsymbol{P}^{\prime}-\hat{A} H_{p}\right)^{T}\left(\Delta \boldsymbol{P}^{\prime}-\hat{A} H_{p}\right)$. 

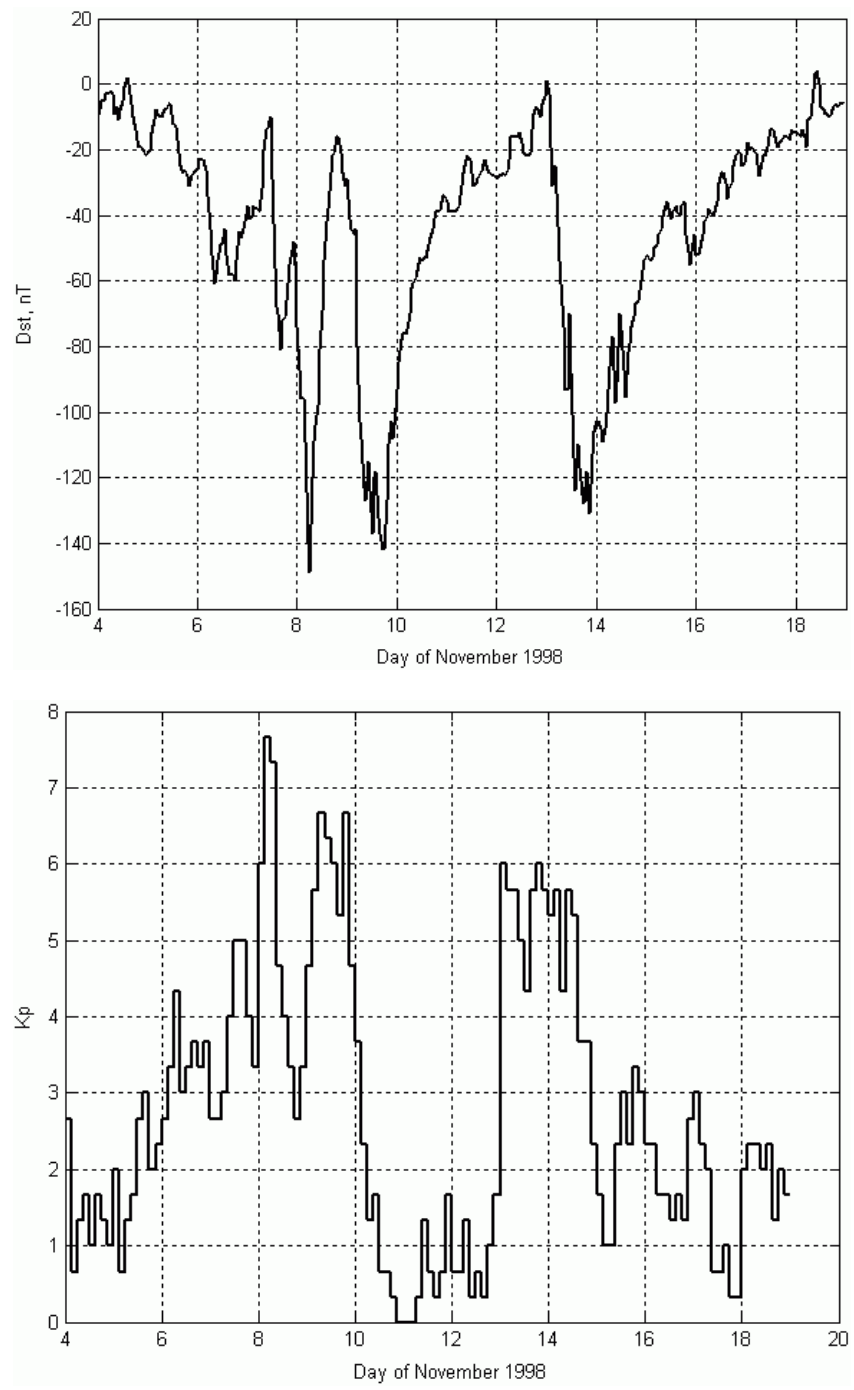

Fig. 2. $D_{s t}$ and $K_{p}$ indexes during the experiment.

In all of the above formulae index " $\mathrm{T}$ " means transposition.

The electron density is related to the plasma frequency by a simple formula

$N=\alpha f_{N}^{2}, \quad \alpha=1.24 \times 10^{10} m^{-3}(M H z)^{-2}$,

the integration of which with reference to (1) gives us Total Electron Content

$T E C=\int_{0}^{h_{s}} N(h) d h=\frac{2}{3} \alpha f_{m}^{2} H_{p}$.

The mean square error of TEC can be estimated as follows, using the above formula:

$s(T E C)=T E C\left(\frac{2 s\left(f_{m}\right)}{f_{m}}+\frac{s\left(H_{p}\right)}{H_{p}}\right)$.

When considering the source of errors in determining parameter $\mathrm{H}_{p}$, the following three factors should be considered: 1)

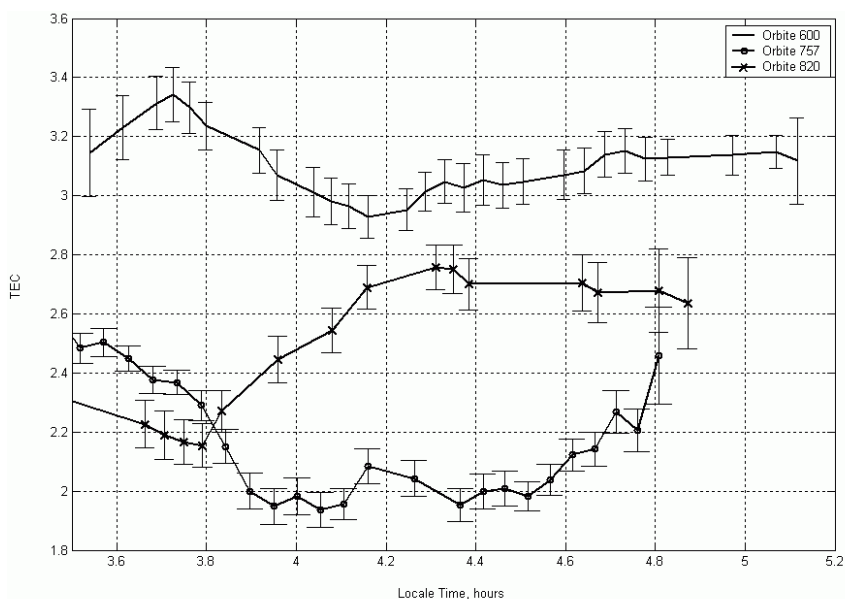

Fig. 3. Temporal variations of TEC (in TECU $=10^{16} \mathrm{el} \times \mathrm{m}^{-2}$ ) for three sample orbits.

errors in group path measurements; 2) non-local measurements (the satellite moves on about $45 \mathrm{~km}$ during the ionogram recording time); 3 ) the choice of the equivalent model for $\mathrm{N}(\mathrm{h})$ as a parabolic dependence. In our calculations the assumption $\mathrm{s}\left(\mathrm{f}_{m}\right)=0.1 \mathrm{MHz}$ was chosen and the second term in formula (10) was approximately twice the first term.

Let us explain an important detail in the TEC determination technique. It is possible to reconstruct N(h)-profiles using trans-ionospheric sounding data (Danilkin et al., 1988). In such problems small errors in the experimental measurements lead to large errors in the solution (Tikhonov and Arsenin, 1979; Zhdanov, 2002). Therefore, even a twoparameter problem of $h_{0}$ and $H_{p}$ determination for parabolic model appears to be difficult. This problem can be resolved only using special regularisation technique (Denisenko et al., 1998).

TEC determination requires a knowledge of a halfthickness $H_{p}$ of the parabola (9). Therefore, the problem was reduced to the one parametric only, which can be resolved by the Least-Squares Method (6). This approach delivers a reliable solution that is tolerant to the errors of experimental measurements.

Moreover, LSM is very useful for $H_{p}$ errors estimation (7), as well as for the monitoring of the interim results. In particular, according to Plackett (1960), mean square error

$\Delta P^{\prime}$ is

$s\left(\Delta P^{\prime}\right)=\sqrt{\frac{S_{\min }}{n-2}}$,

where $S_{\min }$ is calculated from (8). Taking into account $s\left(P^{\prime}\right) \approx s\left(\Delta P^{\prime}\right)$, the authors have found that for all experiments the $s\left(P^{\prime}\right)$ value belongs to the $10-15 \mathrm{~km}$ segment. These estimations correspond to the technical specifications of the AI- 840 ionosonde. Thus, adopted by the authors the $\mathrm{N}(\mathrm{h})$ model for night conditions was proved to be entirely acceptable. 


\section{Discussion}

The results of the TEC calculations for three orbits as a function of local time (the common time interval had been chosen) are shown on Fig. 3.

Before the magnetic disturbances (orbit 600) the value of TEC is maximal, during the storm (orbit 757) it is minimal, and after the storm (orbit 820) the TEC value increases again. It is clear from the graphs that the overall picture illustrates the typical time development of an event with a strongly expressed negative phase (Buonsanto, 1999). A comparison of TEC as a function of the geomagnetic latitude (Fig. 4) shows some interesting details.

Each of the three TEC structures was obtained during a 2$\mathrm{m}$ time period. Therefore, they can be interpreted as almost instantaneous "portraits" of the ionosphere alongside each orbit. Given that the speed of the space station is approximately $8 \mathrm{~km} / \mathrm{s}$, even a large-scale TID with an approximate speed of $1 \mathrm{~km} / \mathrm{s}$ would distort the picture only slightly. From this point of view the spatial structure alongside the orbit 600 is especially interesting. The solid curve in Fig. 4 demonstrates noticeable variations of TEC in the middle-latitude ionosphere for a 10-deg segment of geomagnetic latitudes. These variations exceed the measurement errors represented in Fig. 3. Existence of such variations is difficult to explain from the point of view of standard processes of transport and recombination. The authors suggest that the observed structure can be caused by the TID with an amplitude of about $5 \%$ and a wavelength of approximately $450 \mathrm{~km}$ along the geomagnetic meridian. This is a middle-scale disturbance that can be caused by some local events (Hargreaves, 1992; Brunelli, Namgaladze, 1988).

During the recovery phase (orbit 820 ) the TEC value increases significantly slower for the latitudes higher than 40 degrees. This is caused by a slower process of flux tubes filling with the characteristic time increasing as $\mathrm{L}^{4}$, when we move to a higher L value (Krinberg, Tashchilin, 1984).

The main subject of interest here is the behaviour of the electron density during the storm (orbit 757). The profound trough is clearly visible. Its particular characteristics include a gently sloping equatorial-side wall and a sharply rising polar-side wall. The splitting of the trough in two (MIT and RIT) is noticeable. Splits like that usually start to occur during the main phase of a magnetic storm and they are mostly expressed during the recovery phase due to a plasma movement towards higher latitudes with a different speed (Deminov et al., 1995). Interestingly, the trough is positioned very closely ( $43^{\circ}$ geomagnetic latitude) to its minimal possible position, which according to the latest and most precise models must be about $44^{\circ}$ (Werner, Prolls, 1995) or $43^{\circ}$ latitude (Annaculiev et al., 1997) and usually is the characteristic of a stronger disturbance.

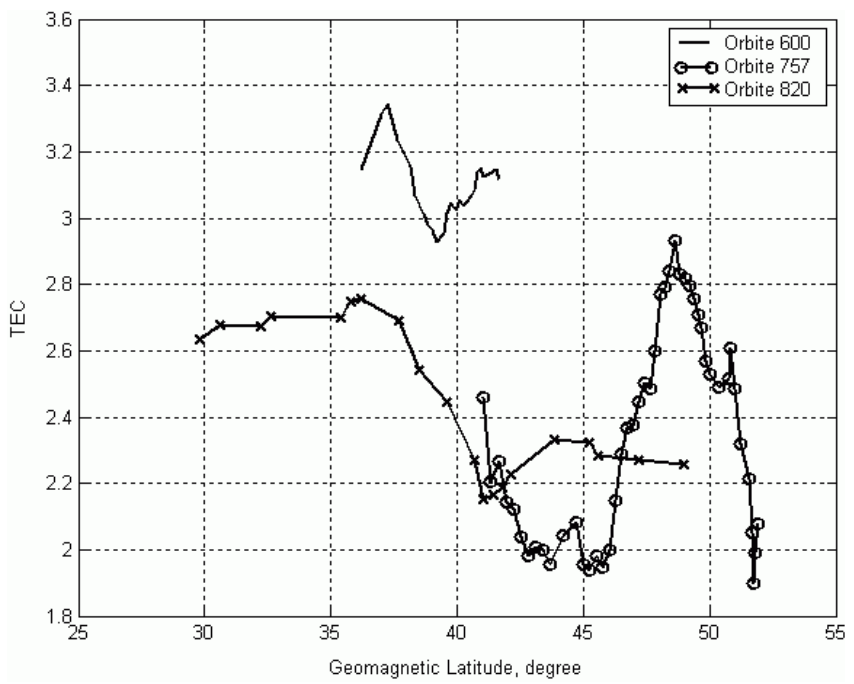

Fig. 4. TEC variations vs. geomagnetic latitude for three sample orbits. Errors of TEC determination are the same as for Fig. 3.

\section{Conclusion}

Today the use of near-Earth space requires a reconstruction of the electron density profiles in the ionosphere in real time with a maximum precision. A major cause of errors in this reconstruction is due to unknown details of the position and shape of the ionisation trough, as well as of the other related structures. The most useful method for a determination of the parameters of these structures is the global ionospheric monitoring performed by low-orbit satellites with an ionosonde on board. The new experimental technique is presented for such monitoring.

The authors have demonstrated by an analysis of data from several orbits of the MIR station during a magnetic storm, that ionospheric monitoring using a topside ionosonde allows us to determine the presence and characteristics of the wave structures of TID type, as well as the position and the shape of an ionospheric trough and some other structures. The possibility of detecting middle-scale TID is of particular interest, especially because the nature of the generating source for this type of TID remains unclear. In addition, an abnormally low position $\left(43^{\circ}\right.$ geomagnetic latitude) of the main ionospheric trough was observed after a series of strong magnetic storms.

The presented technique can be used to study the fine structure of spatial distribution of the electron density in the ionosphere during periods of magnetic storms.

Acknowledgements. Authors gratefully acknowledge the help of Danilkin N.P., Vodolazkin V.I. and Skazik A.I. during the experiment and experimental data processing. The work was carried out by the international team (ID 36) in the framework of the project "Solar Wind disturbances and properties of the upper ionosphere from INTERBALL and MIR data". This teamwork was supported by the International Space Science Institute (ISSI) in Bern, Switzerland.

Topical Editor M. Lester thanks two referees for their help in evaluating this paper. 


\section{References}

Afraimovich, E. L., Kosogorov, E. A., and Leonovich, L. A.: The use of the international GPS network as the global detector (GLOBDET) simultaneously observing sudden ionospheric disturbances, Earth, Planets, and Space, 52, 1077-1082, 2000.

Annakuliev, S. K., Afonin, V. V., Demidov, M. G., and Karpachev, A. T.: The empirical formula for the position of the main ionospheric trough during the magnetic storm, Geomagnetism and Aeronomy, 37(3), 183-187, 1997.

Brunelli, B. E. and Namgaladze, A. A.: Physics of the ionosphere, 528 pp. Nauka, Moscow, 1988.

Buonsanto, M. J.:, Ionospheric storms: A review, Space Sci. Rev. 88, 563-601, 1999.

Buonsanto, M. J., Foster, J. C., and Sipler, D. P.: Observations from Millstone Hill during the geomagnetic disturbances of March and April, 1990, J. Geophys. Res., 97(A2), 1225-1243, 1992.

Calvert, W., Benson, R. F., Carpenter, D. L., Fung, S. F., Gallagher, D. L., Green, J. L., Haines, D. M., Reiff, P. H., Reinisch, B. W., Smith, M. F., and Taylor, W. W. L: The feasibility of radio sounding in the magnetosphere, Radio Sci., 30(5), 1577-1595, 1995.

Danilov, A. D.: F-region reaction to magnetospheric storm, J. Atmos.-Solar Terr. Phys., 63, 441-449, 2001.

Danilkin N. P., Denisenko P. F., and Sotsky V. V.: Peculiarities of the inverse problems of vertical radio sounding of the ionosphere. Adv. Space R., vol. 8, no. 4, p. 91-94, 1988.

Danilkin, N. P.: The results of the satellite radio sounding of the ionosphere in the vicinity of the F-layer maximum, International J. of Geomagnetism and Aeronomy, 2(3), 173-180, 2001.

Danilkin, N. P.: What is the best height for the topside sounding: $1000 \mathrm{~km}$ or $350 \mathrm{~km}$ ? , URSI GA 2002, GP1b.,103, 2002.

Denisenko P. F., Nastasyina N. V., Beloff, N., Sotsky, V. V.: Using the regularization method for electron density height profile reconstruction. Report UAG-105 "Computer aidet processing of ionograms and ionosonde records". March 1998.

Davies, K. and Hartmann, G. K.: Studying the ionosphere with the global positioning system, Radio Sci., 32(4), 1695-1703, 1997.

Deminov, M. G., Karpachev, A. T., Afonin, V. V., Annakuliev, C. K., and Shmilayer, J.: The dynamics of middle-latitude trough during storms. 1. Quality picture, Geomagnetism and Aeronomy, 35(1), 73-81, 1995.

Dymond, K. F.: Foreword to special section: Remote sensing of the low- and middle latitude thermosphere and ionosphere from the ground and from space, J. Geo. Res., 106(A12), 2001JA001100, 30 281-30 282, 2001.

Eliseev, A. Yu., Bezprozvannaya, T. C., and Shchuka, T. I.: The empirical modelling of the ionospheric behaviour during global magnetic storms, Geomagnetism and Aeronomy, 35(2), 148$153,1995$.
Gonzalez, W. D., Joselyn, J. A., Kamide, Y.,. Kroehl, H. W., Rostoker, G., Tsurutani, B. T., and Vasyliunas, V. M.: What is a geomagnetic storm?, J. Geophys. Res., 99(A4), 5771-5792, 1994.

Hargreaves, J. K.: The solar-terrestrial environment. Cambridge University Press. 420 p. 1992.

Hofmann-Wellenhof, B., Lichtenegger, H., and Collins, J.:Global positioning system: Theory and practice, Springer-Verlag Wien, New York, 327 p., 1992.

Karpachev, A. T.: Characteristics of ring ionospheric trough, Geomagnetism and Aeronomy, 41(1), 57-66, 2001.

Krinberg, I. A. and Tashchilin, A. V.: Ionosphere and plasmasphere, Moscow: Science, 189 p., 1984.

Leitinger, R., Ladreiter, H.-P., and Kirchengast, G.: Ionosphere tomography with data from satellite reception of global navigation satellite system signals and ground reception of navy navigation satellite system signals, Radio Sci., 32(4), 1657-1669, 1997.

Muldrew, D. B.: F-Layer ionization troughs deduced from Alouette data, J. Geophis. Res., 70(11), 2636-2650, 1965.

Paul, A. K.: Use of virtual-height slopes for determination of electron density profiles, Radio Sci., 2(10), 1195-1204, 1967.

Plackett, R. L.: Principles of regression analysis. Oxford University Press., p. 173, 1960.

Pulinets, S. A. and Benson, R. F.: Radio-frequency sounders in space, in review of radio science 1996-1999, Oxford Univ. Press, 711-734, 1999.

Rycroft, M. J. and Thomas,J. O.: The magnetospheric plasmapause and the electron density trough at the Alouette 1 orbit, Planet. Space Sci., 18(1), 65-80, 1970.

Scali, J. and Reinisch, B. W.; Storm time studies using digisonde data, Adv. Space Res., 20(9), 1679-1688, 1997.

Schreiner, W. S., Sokolovsky, S. V., Rocken, C., and Hunt, D. C.: Analysis and validation of GPS/MET radio occultation data in the ionosphere, Radio Sci., 34(4), 949-966, 1998.

Szuszczewich, E. P., Blanchard, P., Wilkinson, P., Crowley, G., Fuller-Rowell, T., Richards, P., Abdu, M., Bullett, T., Hanbaba, R., Lebreton, J. P., Lester, M., Lockwood, M., Millward, G., Wild, M., Pulinets, S., Reddy, B. M., Stanislawska, I., Vannaroni, G., and Zolesi, B.: The first real-time worldwide ionospheric prediction network: An advance in support of space-borne experimentation, on-line model validation, and space weather. Geophys. Res. Lett., 25(4), 449-452, 1998.

Tikhonov A. H. and Arsesin, B. Ya.: Resolving methods for illposed problems. Moscow, Science,, p. 286 (in Rus.), 1979.

Werner, S. and Prolss, G. W.: The position of the ionospheric trough - an empirical model based on DE2 observations, Kleinheubacher Berichte, 38, 143-154, 1995.

Williams, D. J. and Mead, G. D.: Magnetospheric physics, proceedings of the international symposium on the physics of the magnetosphere, Washington, 3-13 September 1968.

Zhdanov, M. S.: Geophysical inverse theory and regularization problems. Elsevier, p. 628, 2002. 